\title{
It's not all in the numbers
}

\author{
Mark I. Travin, MD, FASNC \\ Division of Nuclear Medicine, Department of Radiology, Montefiore Medical Center \\ and the Albert Einstein College of Medicine, Bronx, NY
}

Received Feb 21, 2015; accepted Feb 22, 2015

doi:10.1007/s12350-015-0105-8

\section{See related article, pp. 425-435}

Quantitative analysis is an integral part of nuclear cardiology. It is a major strength and a key advantage that separates this technique from other noninvasive imaging methods. Nuclear cardiology is "inherently quantitative" in that image displays depict the number of counts detected by a gamma camera, reflecting the amount of radiotracer in the entity being imaged.

Perhaps the earliest use of quantitative measurements was by Parker et al who, in contrast to a previously reported geometric method, ${ }^{1}$ measured background corrected ${ }^{99 \mathrm{~m}} \mathrm{Tc}$-labeled human serum albumin ventricular blood pool counts from electrocardiographically gated end-diastolic and endsystolic digital planar left anterior oblique images to derive a counts-based left ventricular ejection fraction (LVEF). ${ }^{2}$ Shortly after the introduction of thallium-201 $\left({ }^{201} \mathrm{Tl}\right)$ for myocardial perfusion imaging (MPI), ${ }^{3,4}$ efforts to apply quantitation began. ${ }^{5}$ As the clinical potential of MPI became recognized, ${ }^{6}$ methods to quantitate visual regional tracer uptake were developed. While a multiple slice profile method was considered, ${ }^{7,8}$ circumferential count profile techniques became preferred. ${ }^{9-11}$ Building on these, Garcia et al developed a comprehensive computerized space/time quantitation method. ${ }^{12}$ After applying proximity weighted interpolative background subtraction, for each of three standard planar views, $606^{\circ}$ spaced interval radii originating from the visually determined center of the ventricle were created, with maximal ventricular wall counts along each radius plotted as a function of angular

Reprint requests: Mark I. Travin, MD, FASNC, Division of Nuclear Medicine, Department of Radiology, Montefiore Medical Center and the Albert Einstein College of Medicine, 111 E. 210th Street, Bronx, NY 10467-2490; mtravin@attglobal.net

J Nucl Cardiol 2016;23:436-41.

$1071-3581 / \$ 34.00$

Copyright (C) 2015 American Society of Nuclear Cardiology. coordinates aligned in reference to the apex, normalized to the maximum value. Portions of profiles from patients with suspected disease that were $>2$ standard deviations (SD) below "normal" patient $(<1 \%$ likelihood of coronary disease ${ }^{13}$ ) means were considered abnormal. It was recognized from the outset that profile curves were representations of relative rather than absolute tracer uptake, thus limited in the ability to detect balanced flow reduction.

The advent of single photon emission computer tomography (SPECT) prompted efforts to quantitate three-dimensional distribution of radiotracer, with generation of two-dimensional polar coordinate maps (i.e., "bullseye" displays), thereby enhancing conceptualization of defect distribution and percentages $(\%)$ of abnormal myocardium. ${ }^{14,15}$ Maximal count normalized circumferential profiles were generated from short-axis (SA) slices from the most apical to most basal cuts (analogous to the planar technique), but also from the apical profiles $\left(60^{\circ}-120^{\circ}\right)$ of the vertical long-axis (VLA) slices to be placed at the center of the plot to represent the apex, with the SA profiles mapped as increasingly larger circles toward the base. Similar to planar techniques, data from low CAD likelihood cases were used such that patient counts $>2.5$ SD below the mean were considered abnormal. Sophistication increased after the advent of technetium-99m $\left({ }^{99 \mathrm{~m}} \mathrm{Tc}\right)$ tracers in that geometric methods were modified such that sampling of SA slices used cylindrical coordinates and sampling of the apical region used spherical coordinates, ensuring perpendicular myocardial radial sampling at all points to more accurately measure tracer distribution. ${ }^{16}$ With availability of increased computer power, Germano et al developed an alternative algorithm that replaced circumferential profiles with true three-dimensional sampling, and with the generated sampling rays assessed counts through the entire myocardial thickness from endocardial to epicardial surface ("whole myocardium sampling)," rather than using only maximal counts. ${ }^{17,18} \mathrm{~A}$ total perfusion defect (TPD) parameter were derived, designed to combine 
measures of defect extent, and severity based on counts in each polar map pixel relative to limits from lowlikelihood patients, expressed as a \% of the myocardium, with the TPD difference between stress and rest images quantitating ischemia. ${ }^{19}$

The aforementioned is the basis for a variety of contemporary quantitative techniques routinely applied to enhance SPECT MPI image interpretation. ${ }^{20}$ Compared with visual assessment alone, quantitation improves interpretive reproducibility. ${ }^{21,22}$ Robust diagnostic accuracy is consistently shown, ${ }^{15,23,24}$ with some studies reporting higher accuracy than visual analysis. ${ }^{19,25}$ Quantitation should improve risk stratification, although there are few publications to date in this regard. $^{26,27}$ Nonetheless, TPD was used to measure progression or regression of myocardial ischemia in the Clinical Outcomes Utilizing Revascularization and Aggressive Drug Evaluation (COURAGE) trial, ${ }^{28}$ and is an important element of the multicenter prospective randomized ISCHEMIA study (The International Study of Comparative Health Effectiveness with Medical and Invasive Approaches) that uses a TPD ischemia score $\geq 10 \%$ as one inclusion criteria to assess invasive vs optimal medical therapy. ${ }^{29}$

While MPI remains the most widely used cardiac radiotracer imaging modality, another important strength of nuclear cardiology is its ability to image physiologic processes other than perfusion. Quantitative uptake of ${ }^{201} \mathrm{Tl}$ and ${ }^{99 \mathrm{~m}}$ Tc-based "perfusion", tracers for assessment of the ability of cardiomyocytes to take up and retain tracer has been used for diagnosis and decision making related to myocardial viability. ${ }^{30,31}$ Examination of cardiomyocyte metabolism using 18-fluorodeoxyglucose $\left({ }^{18}\right.$ FDG) relies heavily on quantitative techniques. The Positron Emission Tomography and Recovery following Revascularization (PARR) Trials studying patients with ischemic LV dysfunction used sophisticated geometric and count measurement techniques to assess N-13 ammonia $\left({ }^{13} \mathrm{NH}_{3}\right)$ perfusion and ${ }^{18}$ FDG metabolic uptake, deriving a mismatch score (extent and severity of hibernating myocardium) and a "scar' score as percentages of the myocardium. ${ }^{32-34}$ These values were essential in the PARR-1 trial's derivation of variables predictive of change in LV function, ${ }^{35}$ and were used in PARR-2 to examine utility of PET viability imaging for guidance of patient management. $^{36,37}$

A nuclear cardiology technique studied for many years, but only recently gaining clinical interest in the US, is assessment of cardiac sympathetic adrenergic innervation using analogs of the sympathetic mediator norepinephrine, mostly the SPECT tracer iodine 123 meta-iodobenzylguanidine $\left({ }^{123} \mathrm{I}-m \mathrm{IBG}\right)$, but also PET tracers such as C-11 hydroxyephedrine $\left({ }^{11} \mathrm{C}-\mathrm{HED}\right) .{ }^{38,39}$ Soon after the initial report of human cardiac imaging with ${ }^{123} \mathrm{I}-m \mathrm{IBG},{ }^{40}$ the first systematic study of patients with cardiac disease proposed use of a quantitative heart to mediastinal ratio (HMR) on an anterior planar image, and showed correlation of HMR with LVEF in patients with cardiomyopathy. ${ }^{41}$ Shortly thereafter, the first study showing prognostic utility of ${ }^{123} \mathrm{I}-m \mathrm{IBG}$ imaging in advanced heart failure (HF) analyzed ${ }^{123} \mathrm{I}-m \mathrm{IBG}$ images in terms of the quantitative HMR, finding this value to be more " potent"' than other parameters, including LVEF, in predicting death. ${ }^{42}$ Subsequent reports all relied on the planar HMR in predicting outcome, ${ }^{43}$ culminating in the AdreView Myocardial Imaging for Risk Evaluation in Heart Failure (ADMIRE-HF) study that risk stratified HF patients in relation to an HMR of $1.6 .^{44}$

Nevertheless, although the planar HMR is the essence of much current ${ }^{123} \mathrm{I}-m \mathrm{IBG}$ imaging, considered by some as akin to a biomarker, the utility of tomographic imaging has been unclear. Theoretically, identification of regional defects, especially in areas of preserved perfusion, should identify patients at risk of electrical instability and thus lethal arrhythmias. ${ }^{45-47}$ The need for tomographic imaging is suggested by a recent analysis reporting that planar HMR, although a strong predictor of all-cause mortality, cardiac mortality, and eventual need for heart transplant, likely does not provide enough contrast and 3D detail for highly accurate prediction of arrhythmic events. ${ }^{48}$ Small cohort studies using semiquantitative visual scoring techniques suggest clinical utility for SPECT ${ }^{123} \mathrm{I}-m \mathrm{IBG}$ in assessing arrhythmic risk, ${ }^{49-57}$ but utility in a large trial has not been established. ${ }^{44}$ For PET adrenergic imaging, the recent "Prediction of ARrhythmic Events with Positron Emission Tomography" (PARAPET) trial of tomographic imaging with ${ }^{13} \mathrm{NH}_{3},{ }^{18} \mathrm{FDG}$, and ${ }^{11} \mathrm{C}$-HED in 200 patients with ischemic cardiomyopathy used rigorous quantitative techniques for assessing perfusion, cardiomyocyte metabolism, and adrenergic innervation, finding that an increase in the extent/severity of ${ }^{11} \mathrm{C}$-HED defects was independently associated with higher arrhythmic risk. ${ }^{58}$ However, because ${ }^{11} \mathrm{C}-\mathrm{HED}$ is impractical for most practitioners, development of a robust method for quantitation of SPECT ${ }^{123} \mathrm{I}-m \mathrm{IBG}$ is warranted.

In this issue of the Journal, Clements et al report development of a quantitative technique for assessing SPECT ${ }^{123}$ I- $m$ IBG images ${ }^{59}$ that they tested on images of a 938 patient subset of HF patients ${ }^{44}$ in reference to 40 patient age-matched controls who were enrolled in the ADMIRE-HF trial. ${ }^{60}$ SPECT processing was skillfully performed with iterative reconstruction that included the deconvolution of septal penetration algorithm developed by several of the authors to account for high-energy collimator-penetrating ${ }^{123} \mathrm{I}$ photons. ${ }^{61}$ Voxel count determination used geometric and myocardial sampling techniques previously reported by 
Van Train et al and Garcia et al for MPI. ${ }^{16,23,62}$ The authors, however, recognize unique challenges of adrenergic tomographic imaging which is in many ways conceptually different from perfusion imaging. Among these is that while for MPI there are almost always regions with normal perfusion that can serve as a reference to which count profiles are normalized, for ${ }^{123} \mathrm{I}-\mathrm{mIBG}$ images globally reduced tracer uptake occurs often, more so for patients with HF. Thus the authors designed a "mixed reference" method in which classifying a region as "abnormal" (referred to as "dysinnervation") varied in relation to global tracer uptake measured by the HMR, with this approach helping to overcome an underestimation of abnormality in patients with severe global dysinnervation.

Another challenge is that unlike for MPI in which validity and accuracy of a methodology is customarily assessed in reference to "gold standard" coronary anatomy findings (as flawed as that can be), there is no such standard upon which to assess adrenergic imaging techniques. The authors therefore used comparison of quantitative results in patients with ischemic vs nonischemic heart failure (IHF vs NIHF) as the testing reference, and propose their finding of significantly more severe quantitative dysinnervation in IHF patients to be an initial validation of their methodology. While the approach is reasonable, ${ }^{63}$ perfusion findings can significantly overlap in ischemic and non-ischemic cardiomyopathies $(\mathrm{CM}) .^{64,65}$ In addition, extrapolating perfusion image phenomena to adrenergic imaging is an unproven assumption.

With ${ }^{123} \mathrm{I}-m \mathrm{IBG}$ imaging, lung and liver tracer uptake overlying myocardial walls can make SPECT images difficult to interpret completely, and one would expect impairment of quantitative analysis. The authors recognize this limitation that resulted in frequent need to manually identify the LV region of interest, but report that only 8 of 949 images $(<1 \%)$ were not analyzable. However, it has been this writer's experience that in only about $80 \%$ of SPECT ${ }^{123}$ I- $m$ IBG images can all segments be confidently scored, ${ }^{66}$ in accord with a study using a solid-state camera that reported only $85 \%$ of SPECT ${ }^{123}$ I- $m$ IBG images to be of good or better quality. ${ }^{67}$ Although a technique such as that described by the authors will produce data even for poor quality images, one cannot know if the results are legitimate without more rigorous validation.

While technical and logistic challenges can be overcome, one must also consider that adrenergic imaging assesses a physiologic phenomenon different from perfusion, and therefore be cautious about applying the same interpretive paradigm. With perfusion imaging more extensive and severe defect(s) predict poorer outcome. ${ }^{68}$ However, as an important goal of tomographic adrenergic imaging is lethal arrhythmic risk assessment, how does one know that the size and severity of defect(s) are the parameter of interest? In a subset of ADMIRE-HF patients without an ICD, the likelihood of sudden death was higher in patients with an intermediately decreased (1.30-1.59) than in those with a severely depressed $(<1.30)$ HMR. ${ }^{69}$ Recent reports suggest that intermediate degrees of SPECT ${ }^{123} \mathrm{I}-\mathrm{mIBG}$ abnormalities might indicate higher arrhythmic risk than more extensive, more severe defects. ${ }^{66,70}$ Genesis of arrhythmias is complex, in large part increased by myocardial tissue electrical heterogeneity. ${ }^{71}$ For assessment of arrhythmic risk, nuclear techniques will likely need to go beyond the numbers. While having no dysinnervation is certainly better than having any, perhaps the distribution, pattern, and location of dysinnervation are more important than extent and severity. Dysinnervation distribution may have to include not only what is measured and appears on 2D polar plot displays, but also the gradient between endocardium and epicardium. ${ }^{72}$ Maximal count measurements as used by Clements et al would not completely portray important physiology. The location of dysinnervation also appears important. In studies of patients with Brugada syndrome, Wichter et al found that ${ }^{123} \mathrm{I}-m \mathrm{IBG}$ defects occurred most often in the inferior and inferoseptal walls. ${ }^{56}$ Zhou et al recently reported that decreased ${ }^{123} \mathrm{I}-m \mathrm{IBG}$ counts in the border zone between myocardial scar and normal tissue is better than other parameters in predicting electrophysiologic inducibility. ${ }^{73}$ Thus, new ways of describing adrenergic tomographic image findings, beyond quantitation alone, appear needed.

Quantitation of image findings has been and will continue to be crucially important for nuclear cardiology. Numbers should faithfully portray the physiologic phenomena being examined. Quantitative methods need further development, and will need to be supplemented by defect location and pattern when examining complex pathophysiology such as arrhythmias. Ultimately, quantitative and qualitative findings must be shown useful for guiding patient management as validity can only be assessed in terms of improved patient well being.

\section{References}

1. Zaret BL, Strauss HW, Hurley PJ, Natarajan TK, Pitt B. A noninvasive scintigraphic method for detecting regional ventricular dysfunction in man. N Engl J Med 1971;284:1165-70.

2. Parker JA, Secker-Walker R, Hill R, Siegel BA, Potchen EJ. A new technique for the calculation of left ventricular ejection fraction. J Nucl Med 1972;13:649-51.

3. Lebowitz E, Greene MW, Fairchild R, Bradley-Moore PR, Atkins HL, Ansari AN, et al. Thallium-201 for medical use I. J Nucl Med 1975;16:151-5. 
4. Strauss HW, Harrison K, Langan JK, Lebowitz E, Pitt B. Thallium-201 for myocardial imaging. Relation of thallium-201 to regional myocardial perfusion. Circulation 1975;51:641-5.

5. Goris ML, Daspit SG, McLaughlin P, Kriss JP. Interpolative background subtraction. J Nucl Med 1976;17:7.

6. Ritchie JL, Zaret BL, Strauss HW, Pitt B, Berman DS, Schelbert HR, et al. Myocardial imaging with thallium-201: A multicenter study in patients with angina pectoris or acute myocardial infarction. Am J Cardiol 1978;42:345-50.

7. Berger BC, Watson DD, Taylor GJ, Craddock GB, Martin RP, Teates CD, et al. Quantitative thallium-201 exercise scintigraphy for detection of coronary artery disease. J Nucl Med 1981;22:585-93.

8. Watson DD, Campbell NP, Read EK, Gibson RS, Teates CD, Beller GA. Spatial and temporal quantitation of plane thallium myocardial images. J Nucl Med 1981;22:577-84.

9. Meade RC, Bameah VS, Horgan JD, Ruetz PP, Kronenwetter C, Yeh EL. Quantitative methods in the evaluation of thallium-201 myocardial perfusion images. J Nucl Med 1978;19:1175-8.

10. Vogel RA, Kirch DL, LeFree MT, Rainwater JO, Jensen DP, Steele PP. Thallium-201 myocardial perfusion scintigraphy: Results of standard and multi-pinhole tomographic techniques. Am J Cardiol 1979;43:787-93.

11. Burow RD, Pond M, Schafer W, Becker L. "Circumferential profiles:" A new method for computer analysis of thallium-201 myocardial perfusion images. J Nucl Med 1979;20:771-7.

12. Garcia E, Maddahi J, Berman D, Waxman A. Space/time quantitation of thallium-201 myocardial scintigraphy. J Nucl Med 1981;22:309-17.

13. Diamond GA, Forrester JS. Analysis of probability as an aid in the clinical diagnosis of coronary-artery disease. $\mathrm{N}$ Engl $\mathrm{J}$ Med 1979;300:1350-8.

14. Garcia EV, Van Train K, Maddahi J, Prigent F, Friedman J, Areeda J, et al. Quantification of rotational thallium-201 myocardial tomography. J Nucl Med 1985;26:17-26.

15. DePasquale EE, Nody AC, DePuey EG, Garcia EV, Pilcher G, Bredlau C, et al. Quantitative rotational thallium-201 tomography for identifying and localizing coronary artery disease. Circulation 1988;77:316-27.

16. Garcia EV, Cooke CD, Van Train KF, Folks R, Peifer R, DePuey EG, et al. Technical aspects of myocardial SPECT imaging with technetium-99 m sestamibi. Am J Cardiol 1990;66:22E-31E.

17. Germano G, Kiat H, Kavanagh PB, Moriel M, Mazzanti M, Hsiao$\mathrm{Te} \mathrm{S}$, et al. Automatic quantification of ejection fraction from gated myocardial perfusion SPECT. J Nucl Med 1995;36:2138-47.

18. Germano G, Kavanagh PB, Waechter P, Areeda J, Van Kriekinge S, Sharir T, et al. A new algorithm for the quantitation of myocardial perfusion SPECT. I: Technical principles and reproducibility. J Nucl Med 2000;41:712-9.

19. Slomka PJ, Nishina H, Berman DS, Akincioglu C, Abidov A, Friedman JD, et al. Automated quantification of myocardial perfusion SPECT using simplified normal limits. J Nucl Cardiol 2005; 12:66-77.

20. Slomka P, Xu Y, Berman D, Germano G. Quantitative analysis of perfusion studies: Strengths and pitfalls. J Nucl Cardiol 2012;19:338-46.

21. Xu Y, Hayes S, Ali I, Ruddy TD, Wells RG, Berman DS, et al. Automatic and visual reproducibility of perfusion and function measures for myocardial perfusion SPECT. J Nucl Cardiol 2010;17:1050-7.

22. Berman DS, Kang X, Gransar H, Gerlach J, Friedman J, Hayes S, et al. Quantitative assessment of myocardial perfusion abnormality on SPECT myocardial perfusion imaging is more reproducible than expert visual analysis. J Nucl Cardiol 2009;16:45-53.

23. Van Train KF, Areeda J, Garcia EV, Cooke CD, Maddahi J, Kiat H, et al. Quantitative same-day rest-stress technetium-99 m-sestamibi
SPECT: Definition and validation of stress normal limits and criteria for abnormality. J Nucl Med 1993;34:1494-502.

24. Sharir T, Germano G, Waechter PB, Kavanagh PB, Areeda JS, Gerlach J, et al. A new algorithm for the quantitation of myocardial perfusion SPECT. II: Validation and diagnostic yield. J Nucl Med 2000;41:720-7.

25. Arsanjani R, Xu Y, Hayes SW, Fish M, Lemley M Jr, Gerlach J, et al. Comparison of fully automated computer analysis and visual scoring for detection of coronary artery disease from myocardial perfusion SPECT in a large population. J Nucl Med 2013;54:221-8.

26. Leslie WD, Tully SA, Yogendran MS, Ward LM, Nour KA, Metge CJ. Prognostic value of automated quantification of $99 \mathrm{mTc}-\mathrm{ses}-$ tamibi myocardial perfusion imaging. J Nucl Med 2005;46:204-11.

27. Xu Y, Nakazato R, Hayes S, Hachamovitch R, Cheng VY, Gransar $\mathrm{H}$, et al. Prognostic value of automated vs visual analysis for adenosine stress myocardial perfusion SPECT in patients without prior coronary artery disease: A case-control study. J Nucl Cardiol 2011;18:1003-9.

28. Shaw LJ, Berman DS, Maron DJ, Mancini GB, Hayes SW, Hartigan PM, et al. Optimal medical therapy with or without percutaneous coronary intervention to reduce ischemic burden. Results from the clinical outcomes utilizing revascularization and aggressive drug evaluation (COURAGE) trial nuclear substudy. Circulation 2008;117:1283-91.

29. International Study of Comparative Health Effectiveness with Medical and Invasive Approaches (ISCHEMIA). https://clinicaltrials.gov/ct2/ show/NCT01471522. Accessed 2 Dec 2015.

30. Udelson JE, Coleman PS, Metherall J, Pandian NG, Gomez AR, Griffith JL, et al. Predicting recovery of severe regional ventricular dysfunction. Comparison of resting scintigraphy with ${ }^{201} \mathrm{Tl}$ and ${ }^{99 \mathrm{~m}}$ Tc-sestamibi. Circulation 1994;89:2552-61.

31. Kitsiou AN, Srinivasan G, Quyyumi AA, Summers RM, Bacharach SL, Dilsizian V. Stress-induced reversible and mid-to-moderate irreversible thallium defects: Are they equally accurate for predicting recovery of regional left ventricular function after revascularization? Circulation 1998;98:501-8.

32. deKemp RA, Nahmias C. Automated determination of the left ventricular long axis in cardiac positron emission. Physiol Meas 1996;17:95-108.

33. deKemp R, Ruddy TD, Hewitt T, Dalipaj M, Beanlands R. Detection of serial changes in absolute myocardial perfusion with 82Rb PET. J Nucl Med 2000;41:1426-35.

34. Laubenbacher C, Rothley J, Sitomer J, Beanlands R, Sawada S, Sutor R, et al. An automated analysis program for the evaluation of cardiac PET studies: Initial results in the detection and localization of coronary artery disease using nitrogen-13 ammonia. J Nucl Med 1993;34:968-78.

35. Beanlands RSB, Ruddy TD, deKemp RA, Iwanochko RM, Coates G, Freeman M, et al. Positron emission tomography and recovery following revascularization (PARR-1): The importance of scar and the development of a prediction rule for the degree of recovery of left ventricular function. J Am Coll Cardiol 2002;40:1735-43.

36. Beanlands RSB, Nichol G, Huszti E, Humen D, Racine N, Freeman M, et al. PARR-2 Investigators. F-18-fluorodeoxyglucose positron emission tomography imaging-assisted management of patients with severe left ventricular dysfunction and suspected coronary disease: A randomized, controlled trial (PARR-2). J Am Coll Cardiol 2007;50:2002-12.

37. D'Egidio G, Nichol G, Williams KA, Guo A, Garrard L, deKemp $\mathrm{R}$, et al. Increasing benefit from revascularization is associated with increasing amounts of myocardial hibernation. J Am Coll Cardiol Imaging 2009;2:1060-8.

38. Travin MI. Cardiac autonomic imaging with SPECT tracers. J Nucl Cardiol 2013;20:128-43. 
39. Thackeray JT, Bengel FM. Assessment of cardiac autonomic neuronal function using PET imaging. J Nucl Cardiol 2013;20: 150-65.

40. Kline RC, Swanson DP, Wieland DM, Thrall JH, Gross MD, Pitt $\mathrm{B}$, et al. Myocardial imaging in man with I-123 meta-iodobenzylguanidine. J Nucl Med 1981;22:129-32.

41. Schofer J, Spielmann R, Schuchert A, Weber K, Schlüter M. Iodine-123 meta-iodobenzylguanidine scintigraphy: A noninvasive method to demonstrate myocardial adrenergic nervous system disintegrity in patients with idiopathic dilated cardiomyopathy. J Am Coll Cardiol 1988;12:1252-8.

42. Merlet P, Valette H, Dubois-Randé J, Moyse D, Duboc D, Dove P, et al. Prognostic value of cardiac metaiodobenzylguanidine in patients with heart failure. J Nucl Med 1992;33:471-7.

43. Verberne HJ, Brewster LM, Somsen GA, van Eck-Smit BL. Prognostic value of myocardial 123I-metaiodobenzylguanidine (MIBG) parameters in patients with heart failure: A systematic review. Eur Heart J 2008;29:1147-59.

44. Jacobson AF, Senior R, Cerqueira MD, Wong ND, Thomas GS, Lopez VA, et al. Myocardial iodine-123 meta-iodobenzylguanidine imaging and cardiac events in heart failure. Results of the prospective ADMIRE-HF (AdreView Myocardial Imaging for Risk Evaluation in Heart Failure) study. J Am Coll Cardiol 2010;55:2212-21.

45. Minardo JD, Tuli MM, Mock BH, Weiner RE, Pride HP, Wellmann HN, et al. Scintigraphic and electrophysiologic evidence of canine myocardial sympathetic denervation and reinnervation produced by myocardial infarction or phenol application. Circulation 1988;78:1008-19.

46. Zipes DP. Influence of myocardial ischemia and infarction on autonomic innervation of heart. Circulation 1991;84:1709-14.

47. Gerson MC, Abdallah M, Muth JN, Costea AI. Will imaging assist in the selection of patients with heart failure for an ICD? J Am Coll Cardiol Imaging 2010;3:101-10.

48. Verschure DO, Veltman CE, Manrique A, Somsen GA, Koutelou $\mathrm{M}$, Katsikis A, et al. For what endpoint does myocardial ${ }^{123} \mathrm{I}-\mathrm{MIBG}$ scintigraphy have the greatest prognostic value in patients with chronic heart failure? Results of a pooled individual patient data meta-analysis. Eur Heart J Cardiovasc Imaging 2014;15:996-1003.

49. Stanton MS, Tuli MM, Radtke NL, Heger JJ, Miles WM, Mock $\mathrm{BH}$, et al. Regional sympathetic denervation after $\mathrm{MI}$ in humans detected noninvasively using I-123-MIBG. J Am Coll Cardiol 1989;14:1519-26.

50. McGhie AI, Corbett JR, Akers MS, Kulkarni P, Sills MN, Kremers $\mathrm{M}$, et al. Regional cardiac adrenergic function using I-123 MIBG SPECT imaging after acute myocardial infarction. Am J Cardiol 1991;67:236-42.

51. Simões MV, Barthel P, Matsunari I, Nekolla SG, Schömig A, Schwaiger $\mathrm{M}$, et al. Presence of sympathetically denervated but viable myocardium and its electrophysiologic correlates after early revascularised, acute myocardial infarction. Eur Heart J 2004;25:551-7.

52. Arora R, Ferrick KJ, Nakata T, Kaplan RC, Rozengarten M, Latif F, et al. I-123 MIBG imaging and heart rate variability analysis to predict the needs for an implantable cardioverter defibrillator. J Nucl Cardiol 2003;10:121-31.

53. Bax JJ, Kraft O, Buxton AE, Fjeld JG, Pařízek P, Agostini D, et al. ${ }^{123}$ I- $m$ IBG Scintigraphy to predict inducibility of ventricular arrhythmias on cardiac electrophysiology testing: A prospective multicenter pilot study. Circ Cardiovasc Imaging 2008;1:131-40.

54. Boogers MJ, Borleffs CJ, Henneman MM, van Bommel RJ, van Ramshorst J, Boersma E, et al. Cardiac sympathetic denervation assessed with 123-Iodine metaiodobenzylguanidine imaging predicts ventricular arrhythmias in implantable cardioverter-defibrillator patients. J Am Coll Cardiol 2010;55:2769-77.
55. Marshall A, Cheetham A, George RS, Mason M, Kelion AD. Cardiac iodine-123 metaiodobenzylguanidine imaging predicts ventricular arrhythmia in heart failure patients receiving an implantable cardioverter-defibrillator for primary prevention. Heart 2012;98:1359-65.

56. Wichter T, Matheja P, Eckardt L, Kies P, Schäfers K, SchulzeBahr E, et al. Cardiac autonomic dysfunction in Brugada syndrome. Circulation 2002;105:702-6.

57. Paul M, Wichter T, Kies P, Gerss J, Wollmann C, Rahbar K, et al. Cardiac sympathetic dysfunction in genotyped patients with arrhythmogenic right ventricular cardiomyopathy and risk of recurrent ventricular tachyarrhythmias. J Nucl Med 2011;52: 1559-65.

58. Fallavollita JA, Heavey BM, Luisi AJ Jr, Michalek SM, Baldwa S, Mashtare TL, et al. Regional myocardial sympathetic denervation predicts the risk of sudden cardiac arrest in ischemic cardiomyopathy. J Am Coll Cardiol 2014;63:141-9.

59. Clements I, Garcia E, Chen J, Folks R, Butler J, Jacobson A. Quantitative iodine 123 meta-iodobenzylguanidine (MIBG) SPECT imaging in heart failure with left ventricular systolic dysfunction: Development and validation of automated procedures in conjunction with technetium-99m tetrofosmin myocardial perfusion SPECT. J Nucl Cardiol 2015. doi:10.1007/s12350-0150097-4.

60. Jacobson AF, Lombard J, Banerjee G, Camici PG. 123I-mIBG scintigraphy to predict risk for adverse cardiac outcomes in heart failure patients: Design of two prospective multicenter international trials. J Nucl Cardiol 2009;16:113-21.

61. Chen J, Garcia EV, Galt JR, Folks RD, Carrió I. Improved quantification in I-123 cardiac SPECT imaging with deconvolution of septal penetration. Nucl Med Commun 2006;27:551-8.

62. Garcia EV, Faber TL, Cooke CD, Folks RD, Chen J, Santana C. The increasing role of quantification in clinical nuclear cardiology: The Emory approach. J Nucl Cardiol 2007;14:420-32.

63. Rischpler C, Nekolla S, Schwaiger M. PET and SPECT in heart failure. Curr Cardiol Rep 2013;15:337. doi:10.1007/s11886-012-0337-z.

64. Wu YW, Yen RF, Chieng PU, Huang PJ. Tl-201 myocardial SPECT in differentiation of ischemic from nonischemic dilated cardiomyopathy in patients with left ventricular dysfunction. J Nucl Cardiol 2003;10:369-74.

65. Yao S, Qureshi E, Nichols K, Diamond GA, DePuey EG. Prospective validation of a quantitative method for differentiating ischemic versus nonischemic cardiomyopathy by technetium-99m sestamibi myocardial perfusion single-photon emission computed tomography. Clin Cardiol 2004;27:615-20.

66. Verberne H, Henzlova M, Jain D, Van Eck Smit BLF, Carrió I, Jacobson A, et al. ${ }^{123} \mathrm{I}-\mathrm{mIBG}$ and $99 \mathrm{mTc}$-tetrofosmin SPECT for prediction of arrhythmic risk in ischemic heart failure patients. J Nucl Med 2014;55:182.

67. Gimelli A, Liga R, Giorgetti A, Genovesi D, Marzullo P. Assessment of myocardial adrenergic innervation with a solidstate dedicated cardiac cadmium-zinc-telluride camera: First clinical experience. Eur Heart J CV Imaging 2014;15:575-85.

68. Hachamovitch R, Berman DS. The use of nuclear cardiology in clinical decision making. Semin Nucl Med 2005;35:62-72.

69. Chirumamilla A, Travin MI. Cardiac applications of 123I-mIBG imaging. Semin Nucl Med 2011;41:374-87.

70. Verberne HJ, Henzlova MJ, Jain D, van Eck-Smit BLF, Carrió I, Jacobson AF, et al. Regional myocardial mismatch between ${ }^{123} \mathrm{I}$ MIBG and ${ }^{99 \mathrm{~m}}$ Tc-tetrofosmin SPECT for the prediction of arrhythmic events in ischemic heart failure patients. J Nucl Cardiol 2014;21:799.

71. Tomaselli GF, Zipes DP. What causes sudden death in heart failure? Circ Res 2004;95:754-63. 
72. Luisi AJ Jr, Suzuki G, Dekemp R, Haka MS, Toorongian SA, Canty $\mathrm{JM} \mathrm{Jr}$, et al. Regional 11C-Hydroxyephedrine retention in hibernating myocardium: Chronic inhomogeneity of sympathetic innervation in the absence of infarction. J Nucl Med 2005;46:1368-74.
73. Zhou Y, Zhou W, Folks RD, Manatunga DN, Jacobson AF, Bax JJ, et al. I-123 mIBG and Tc-99m myocardial SPECT imaging to predict inducibility of ventricular arrhythmia on electrophysiology testing: A retrospective analysis. J Nucl Cardiol 2014;21:913-20. 